\title{
Ontological Reflections on What There Is
}

\author{
Matjaž Potrč1, Vojko Strahovnik ${ }^{2 *}$ \\ ${ }^{1}$ Faculty of Arts, University of Ljubljana, Ljubljana, Slovenia \\ ${ }^{2}$ Faculty of Theology, University of Ljubljana, Ljubljana, Slovenia \\ Email: matjaz.potrc@guest.arnes.si, ${ }^{\star}$ vojko.strahovnik@teof.uni-lj.si
}

How to cite this paper: Potrč, M., \& Strahovnik, V. (2019). Ontological Reflections on What There Is. Open Journal of Philosophy, 9, 140-151.

https://doi.org/10.4236/ojpp.2019.92010

Received: March 29, 2019

Accepted: May 5, 2019

Published: May 8, 2019

Copyright (C) 2019 by author(s) and Scientific Research Publishing Inc. This work is licensed under the Creative Commons Attribution International License (CC BY 4.0).

http://creativecommons.org/licenses/by/4.0/

\section{(c) (†) Open Access}

\begin{abstract}
Ontology is the name of the philosophical discipline that provides answers about what there is. The view laid out in the paper, i.e. austere realism, is realistic in that it defends the existence of a thought and language independent world. It is also inclined towards austerity in that it does not take this world to be as richly ontologically populated with entities as common sense initially presupposes. Yet it is a view that results from common sense taking a reflexive attitude about its ontological commitments. Despite its austere consequences, according to this view, many thoughts and sentences expressed by common sense are true, provided that truth is not considered as direct correspondence, i.e. not as the ultimate ontological correspondence to the world. This is enabled by the construal of truth as indirect correspondence that merges the world and contextually operative semantic standards. Such a combined ontological cum semantic view seems a plausible and a well defendable position.
\end{abstract}

\section{Keywords}

Austere Realism, Monism, Indirect Correspondence

\section{Introduction: Inclusivist Approaches in Philosophy}

Philosophy has to do with several basic questions such as: What can I know? What should I $d o$ ? What is there? The first of these questions is dedicated to knowledge and to a discipline investigating its forms and preconditions, epistemology. The second question is responded by a theory of action if the deal is to clarify preconditions of one's activity and by moral philosophy if the stress is put upon the appropriateness and moral correctness of one's deeds. The third among the mentioned questions deals with the existence, with the world.

The three mentioned questions are thus addressed by philosophical disciplines of epistemology, moral theory and ontology. There are several other areas of 
philosophy, but we briefly consider just mentioned ones. If we take a look at these areas, one impression is that they advance from more subjective towards the rather objective ones. Our knowledge seems to be a predominantly subjective enterprise: it deals with what we know, with our proper epistemic ability. Our actions and their consequences with which moral philosophy deals seem to be spanned between our attitudes, decisions and actions on the one side and by their impact on the community we live in on the other. The third mentioned philosophical discipline, ontology, does not seem to harbour any essentially subjective side. It certainly looks like the most objective between the three mentioned areas.

There is some truth captured in the above statements. But some opposite features to the ones just mentioned may also be involved in the characterization of the disciplines. We said that epistemology seems to be a subjective philosophical discipline, putting stress on the evidential considerations that one forms one's beliefs on. But then we also claimed that epistemology, at least in some guises, comes with objective pretensions, such as those that characterize the epistemological approach called reliabilism. Reliabilism deals with the objective reliability of epistemic processes in respect to the environment. Action directing and evaluating moral theory needs to find its balance between subjective and objective pretensions, between general moral principles and their absence with turning to particular circumstances as reasons for action (Strahovnik, 2008). General principles seem to guide our actions and they seem to serve as support for their evaluation. But several principles often come to be involved in a single situation that we confront while acting. Then we need to assess the situation by helping ourselves with the intuitive insight. As thereby the concrete situation increases in its importance, one may wish to push a little bit further and prioritise the importance of a particular situation and particular judgment as such. Is there a similar dialectics to be expected in ontology as well? We will bet that such is the case indeed.

Ontology has the most objective area in its vision: the existence and the world (Bartelj, 1994). Ontology as a philosophical discipline is also involved in the business of laying out and straightening the categories that are employed in assessing the independently existing external world. But these categories depend upon language and thought and therefore again, at least in part, upon the subjective capacity of the involved persons. Let us try with a preliminary approach, before immersing ourselves into some details. The tension in ontology is between several manners in which existence may be recognized. We may opt for the existence of the many, or again for the existence of one entity. If we take the first option, it will be consistent with the views of common sense and our subjective experience of the world, whereas this will not be the case for the second one. But a closer look at the commitments of common sense may reveal that the monistic consequence, i.e. the recognition of the existence of one entity, follows from them. It then turns out that despite its endorsing monistic outlook, common sense can still retain a view that its claims about the many are true (Stra- 
hovnik, 2018) about still is consistent with its previous allowing for the existence of the many.

In this quick overture we have preliminarily characterized the inclusivist approach in philosophy for the disciplines of epistemology, moral theory and ontology. Questions in philosophy often come in exclusive or disjunctive proposals, e.g. either reliabilism or evidentialism, either generalities or particular situations, either many or just one. However, the dialectics of engagement in answering the mentioned questions reveals that an inclusive outcome is really preferable. Such an inclusivist approach will be quickly elaborated for the area of ontology in what follows.

\section{Ontology and What There Is}

Ontology is the philosophical discipline dealing with the question of existence, with the question about what there is. In order to answer this question, you can begin by taking a look around you. There is a chair, a lamp, a book. There are apples and pears. And there is a mountain. There is your state of being bored or excited about all of these things. There are entities and properties. There are complex entities and events such as symphonies and symphonic concerts.

Philosophers have tried to answer questions of ontology in several manners. Some have pointed out that questions of being pertaining to ontology should not be confused with questions about the things that we encounter on an everyday basis in our interactions with the surrounding world. They have thus distinguished between ontological and between ontic questions. Ontology has to do with the basic questions of being, whereas the everyday existing stuff belongs to the area of the ontic. If you go this way then you point out the ontological difference as the difference between the ontology and the ontic. Once you comply with the requirements of ontological difference, you will not be prone anymore to confuse the ontological and the ontic. In other words, you will not be inclined anymore to confuse your cup of tea that's sitting on your table right now with the ultimate ontological entity. The approach taken here tries to respect the requirements of ontological difference.

Other philosophers have tried to establish criteria for existence. One criterion would be as follows: "Admit into your ontology whatever can take a value of a bound variable". A variable is a general substitute mark for a range of values that it may take. Take the variable " $\mathrm{x}$ " and let us determine that it ranges over xylophones, where the xylophone is a "percussion instrument consisting of a series of wooden bars graduated in length to produce the musical scale, supported on belts of straw or felt, and sounded by striking with two small wooden hammers", according to dictionary. There may be several such musical devices, xylophones "a", "b", "c" in this room. In order to distinguish them, we may resort to the convenient convention of naming them, say "Albert", "Bruno" and "Cain". "a", " $\mathrm{b}$ ", "c" then stand for individuals, they are names for these individual entities. Whereas " $\mathrm{x}$ " is not a name and rather it is a variable. It is a placeholder for any 
of the potential names that may range under it. As such a mentioned kind of general placeholder, the " $x$ " then may take several values. In fact, any old xylophone may be ranged under the scope of " $x$ " once as we decide that " $\mathrm{x}$ " is a variable whose potential values are xylophones. But again, notice that " $x$ " as such, as unbound, does not actually range over any of xylophones. The potential filling weight for variable " $\mathrm{x}$ " comes the moment as the variable is bound by the quantifier. There are two quantifiers, the existential (E) and the universal (V). Notice that as such, standing all alone, the variable " $\mathrm{x}$ " has no actual value. It does not refer to any individuals, in the manner in which the names "a", "b", "c" do. But once as the variable is bound by the quantifier, take " $\mathrm{Ex}$ " which goes for "there exists an x", or "Vx" which goes for "all x", the criterion for the existence shifts closer. In fact, in order to state that there is a xylophone, we would have to state there exists an $\mathrm{x}$, such that this $\mathrm{x}$ is a xylophone, or such that it has the property $\mathrm{X}$ of being a xylophone if you wish. "Ex Xx" therefore reads "There exists an $\mathrm{x}$ such that this $\mathrm{x}$ is a xylophone". Notice that variable " $\mathrm{x}$ " as such is not committed to anything existing, that it is just a placeholder. But once as the variable " $\mathrm{x}$ " is bound by the quantifier, be it the existential or universal quantifier, one gets committed to the existence of xylophones, in our case. One could just take "a" as the name of the individual xylophone Albert, and this name would designate some existing entity. In order to get a criterion for existence though, one rather should recur to cases of a bound variable. Taking this approach then, one can propose as such criterion

(B) "To be is to be a value of a bound variable".

What did one accomplish by establishing such a criterion? One has given the conditions under which to accept something as existing. According to this criterion one is committed to the being of whatever a variable that is bound under the existential or universal quantifier ranges over. We can say that criterion (B) offers conditions for ontological commitment.

What is an ontological commitment, really? It describes whatever we are committed to as having existence. If you take a look at this, then it turns out that (B) operates in the area of the ontic and not of that of the ontological, according to the above ontological difference approach to ontology. Answering to such a charge, the supporter of (B) may point out that it is not really clear what the ontological covers on its turn, in contradistinction to the ontic. By establishing (B) and applying it to the xylophones, we at least know what are the criteria of existence for xylophones. But the defender of ontological difference will have a hard time to explain what the ontology ranges over. He will have difficulty to answer the question of what area is covered by the commitments of ontology. Is the deep ontology advocate committed to the Being? But if so, he should show us the range of Being. If he can't, we rather stay with xylophones, cats and possibly with sunsets, but not with the Being.

The approach proposed here respects both the criterion (B) of ontological 
commitment and the ontological difference. Just how can one do this? To make a long answer short in a preliminary manner, such a move can be achieved by taking the inclusive approach with respect to what there is. The inclusive approach attempted here will be attempted by embracing the underlying contextual variability in respect to the ontological questions.

One thing that the criterion about what there is may wish to cover is the difference between the real and between the fictional entities. The cup in front of me is real, so it seems. But Little Red Riding Hood does not have the same kind of existence. According to the distinction introduced by the Slovene philosopher Ernst Mally (1926) (honored by Edward Zalta (1988) and many others), one can describe the difference by the fact that the cup of tea on my desk exemplifies properties such as being warm, being of yellow color. Whereas Little Red Riding Hood, as a fictional object, together with Sherlock Holmes, just encode the properties such as wearing a red hat and a basket, or again being resident of London Town. Notice that under sufficient scrutiny, I can identify any property of the really existing cup of tea sitting on my desk, such as its weight. But the fictional object such as Little Red Riding Hood may fail to exhibit some properties that we would expect her to. Just in order to take an example, Little Red Riding Hood stays indeterminate as to the color of her eyes. This property is just not mentioned anywhere in the fable. The property of the cup of tea that exists and sits on our table, the property of being yellow is vague. Indeed, as one looks at our cup, one can see that its yellow color is not uniform and that there are different shades in which it comes, under variable conditions of illumination. On the other hand, the red color of Little Red Riding Hood as a fictional object is non-vague and uniform, unless otherwise characterized in the story. Besides to the difference between ontology and the ontic, and besides to the criterion of ontological commitment in determining of what there is, there are thus a range of other issues in ontology as well, such as the question what is the kind of existence proper to fictional objects, and how would these objects satisfy criterion (B).

So ontology has to do with a variety of issues and questions. Yes, it seems, first of all, a philosophical discipline engaged with questions about what there is. And this question seems to pertain to the matters external to one's mind and language, to the matters having to do with the mind and language independent world. But we have seen that ontology also deals with such potentially abstract matters as is the Being, and with fictional entities, to which one at least may turn out to be committed under the criterion (B). In fact, one is committed to the appearance of a big bad wolf in the frame of the Little Red Riding Hood fable, whereas one is not committed to the existence of an elephant in the same fable. But if so, then at least a part of ontology as the philosophical discipline investigating what there is happens to be closely linked to the matters of language and thought. For Little Red Riding Hood is a creation of language and thought, and ontology has to find an answer to the status of its existence, either by relying 
upon (B) or upon some other criterion. In fact, metaphysicians such as Aristotle and Brentano (1981) who laid out the basis for ontology dealt with categories (mind and language) stuff as underlying an ontological investigation. And some linguists, such as Emile Benveniste (1958), also were concerned with the question of the intertwining force of ontological and linguistic-mind related ontologies. It perhaps turns out that, just like Simon Blackburn (1984) claims, the main quest in philosophy happens in the triangle whose corners represent language, mind and the external world. All of them then come together, but the weight of each of the involved elements will vary according to the specific approach that one takes. (Quine (1948) wrote a paper entitled "On What There Is" and Terry Horgan (1993) wrote a paper "On What There Isn't”, pointing out the diversity of the possibly non-existent.)

\section{Realism and the Existence of a Thought and Language Independent World}

After this preliminary investigation, we can make some choices. Whatever the entities that exist or that one may be committed to by respecting the criterion (B), there are the following possibilities opened to an ontologist. Either there are many entities out there, or again there is just one, or there is none. The first view may be called ontological pluralism, the second one ontological monism, and the third one ontological nihilism.

Ontological nihilism claims that nothing exists. It is our gut feeling that versions of ontological nihilism are deeply misguided. It just seems to us that there is a real material world out there and that denying this option would bring us into improper consequences. One way in which one may understand ontological nihilism is perhaps by claiming that the world is just our representation. However, there seem to be two problems with such a view. We may well be brains in a vat, under the skeptical scenario, i.e. we could be in a position where whatever we experience is just our projection. Although we reckon that this might be a genuine possibility pertaining to our experiential world, we first think that it does not lead to a genuine ontological position, and that it stays an epistemically centered view. But matters of epistemic access cannot result in ontological facts. We will take an example which we remember from Georges Rey (1983) (discussing psychological categorization issues) and we will arrange it here for our usage. There is one thing if the cow is in the marketplace right now. But it is quite a different question whether I know that the cow is in the marketplace. The narrow nihilism just described seems to confuse epistemic for ontological issues. Another possible way for a nihilist to go is, as already mentioned, in claiming that nothing is composed. However, realize that if nothing is ever composed, there still need to exist elements, such as atoms, quarks, hadrons, or neutrinos, say, and the view is then that these do not ever compose anything such that it could satisfy the criterion of ontological commitment (B). But of course, it seems to us that such a view has to presuppose first that bunch of these atoms, thus of 
entities exist. And if this is true, then it is not actually a version of ontological nihilism. Again, we would dispute the presupposition that there are atoms, that the world is divisible into atoms. Anyway, nihilism does not seem a viable option to us in any of its here discussed guises. The bottom line is that there is something out there that genuinely exists, the material world.

Ontological pluralism seems to be a more acceptable option. It is an option that is first of all close to the views of common sense, at the very start of its engagement into the matters of ontology. Ontological pluralism is the view that there are many things out there, such as stones, chairs and cats, the matters which are called by Quine "middle-sized dry goods", so that they would not be confused by the stuff, say water, magma or snow. Middle-sized dry goods may be counted, whereas chunks of water may not be so easily identified, and neither can they conveniently be counted. Obviously, middle-sized dry goods go hand in hand with the criterion (B) of ontological commitment (Quine, 1953), for finally, they are the things to which we are inclined to be ontologically committed in a natural manner. If someone asks us what is out there, stones, chairs and cats will be first items that we will feel exist out there. We have sympathies with pluralism, but just in the earlier mentioned ontic and not in the deep ontological way, if we may refer to the previous discussion involving ontological difference. More about why we think ontological pluralism cannot be right will be discussed in a moment, as the very criteria for identifying dry goods will be put into question by the reflective attitude taken by common sense engagements themselves.

If it turns out that ontological pluralism might be questioned, as already hinted at, then the option that stays is ontological monism (Potrč, 2003). Ontological monism claims that there is just one world out there, and therefore that the existence of a plurality of entities is questionable. It seems to us that there is just one material world out there indeed and that this world is independent of language and thought.

\section{Austere Realism and Ontological Monism}

If there is just one world out there, i.e. if ontological monism is right, then this has to be called an ontologically austere position (Horgan \& Potrč, 2008). The position is ontologically austere just because it does not allow for the existence of the many, thus in that it welcomes the acceptance of ontological monism.

Common sense presupposes a rich quantity and diversity of existing entities, such as just mentioned stones, chairs and cats. The ontological position of austere realism denies this abundance. Here is the beginning thought into this direction. If stone or chair would be independently existing entities, two in the plurality of many existing things out there, an ontological criterion may demand distinguishing their substances from their accidental properties. But just where is the substance of the stone? Is it materially present out there? And where is the substance of a cat? Is it in its DNA string? Both of these proposals are questionable. And again, the supposed existence of the involved properties is long from 
being settled either. This is just a preliminary hint into the direction why one might think that the austere ontological realism may be more appropriate than is the ontological pluralism.

Zeno of Elea (Diels \& Kranz, 1951) with his known paradoxes was the pupil of the first monist and ontologically austere guy Parmenides. This one believed that there is just one world, round and without any distinction of qualities in it. Whatever we perceive, he thought, is just an illusion. But as philosophers, we should aim about hitting the road of truth. We agree with Parmenides monism and ontological austerity, i.e. with his denial of the many. We disagree with his denial of diversity and dynamics inherent to the one material world. We also disagree with his distinction between truth and illusion. We can sort this last one much more appropriately by respecting the ontological difference and by a recurrence to the matters contextual. Thereby, in the end, we are able to inclusively and in the spirit of compatibilism, save intuitions of common sense. But right now, stressing the austere side of the enterprise, we have to deny the commitments to the many presupposed by common sense, in order to promote ontological monism.

It seems to be in straight conflict with common sense to deny the existence of the many existing entities in one's ontology (Strahovnik, 2018). Yet we wish to claim that such denial of the ontological existence of the many may be derived from the views of common sense itself, once as it hits some reflective road. Common sense initially thus accepts stones, chairs and cats. But if common sense happens to turn reflexive, then it finds reasons to deny the existence of these entities.

Take the question of vagueness. All of the mentioned entities posited by common sense are vague. Stone rolls down the hill, small fractions of its matter get sprinkled, yet it still stays the same stone. But this shows that it is a vague entity. The chair gradually wears out as we use it, yet it is still the same chair, despite that it loses some matter. Then we may happen to exchange parts of it with newer ones, and it will still be the same chair. So a chair is a vague entity. Not to mention the cat. It starts to live, it grows, the material that it consists of gets changed all the time, in a kind of fountain flow manner. Yet it still stays the same old cat. No doubt, a cat is a vague item, if ever there was one. Now, if all of these supposed entities are vague a bit, they are actually vague all the way down. But if this is the case, then the proper criteria of identity do not exist. And if so, these items really cannot be claimed to ontologically exist either. In this case, there cannot really be any ontological separate entities around, and pluralism is wrong. But if ontological nihilism and pluralism cannot be accepted, then ontological monism stays as the acceptable alternative. This is the result of the common sense deliberation itself, in the case where common sense switches into a reflexive mode.

Here is another reflection of common sense leading to the same conclusion to abandon the plurality of the existent. It certainly seems insensible to think that there is a plurality of things out there that get composed in an arbitrary manner. 
It is then plausible to advance a criterion that we can dub Non-Arbitrariness of Composition (NAOC), claiming exactly that there cannot be a bunch of arbitrarily composed items out there. One needs a principle in order to comply with requirements of ontology, in order that one can allow for the existence of all these things. Take the Special Composition Question (SCQ; van Inwagen, 1990) which asks under what conditions entities may compose another entity. Here is one candidate principle that may provide an answer to SCQ and thus comply with NAOC. An easily understandable principle is

(Contact) Things compose an entity if they are in contact.

But here is a strong intuitive example undermining our trust in (Contact). If (Contact) is in power, then there is a new entity coming into existence as we start shaking hands, an entity that eventually ceases to exist once as we stop shaking hands. But this is implausible. And further on it turns out that there is no such principle that would satisfy the requirements of NAOC by providing an appropriate answer to SCQ. Thus, our search for a principle underlying the existence of many fails. Thus, there just exists one out there and not many. This reflective attitude of common sense should be respected we think, and the existence of one material world should be admitted instead.

\section{Truth and Correspondence}

We came to the result of accepting the existence of just one material world, as the consequence of common sense going reflective upon its ontological commitments. This now comes down to our acceptance of ontological monism, the view that there is just one world out there, without any parts. This is the matter of ontological austerity. And this world is a rich and dynamical (Potrč, 2003) material world. Many people have trouble understanding how there can be ontological richness and diversity if there are no parts, how to account for internal relations in this case. And then one realized that relations presuppose the existence of the many parts. But there are no parts in the one material entity or the object Blobject, according to the monistic presupposition. How there may well be rich dynamics even if there are no parts in the material world may be illustrated by the example of the jello children use to play with. They stretch it and bind it. So there is rich dynamical activity going on in the jello, taking a zoom at one point in the jello while the thing gets stretched. It gets in several dynamical relations with its surrounding, a lot of dynamics is certainly going on with it. But there are no parts in such a case involved. The jello metaphor makes it possible for there to be dynamical rich activity in the one material world without parts. Now, it is a realistic possibility that such is also the case with our world: it is a material rich dynamical world without any parts. Actually, some scientific hypotheses about the nature of our universe support such a conclusion: Taking the phenomenon of quantum strangeness. In down to earth terminology accessible to us as philosophers: If a supposed particle quantum is turning in one direction here, its quantum counterpart somewhere in Alpha Centauri is turning into the 
opposite direction because of this fact. So the universe must be interwoven. Monistic view of the universe is thus a possible scientifically supported option.

Now let us say that we are willing to accept the monist option now. One hard question remains though. Isn't the view that there are no cats around, and no chairs, just plainly and simply a lunatic view? In order to answer this question, we will take recourse to the earlier discussed ontological difference, and to some semantical considerations related to it. Respecting the ontological difference (die ontologische Differenz, if you prefer it in German language, although we wonder why the term Unterschied wasn't used instead) means respecting the truth that your cat just isn't the last ontological basic item. Your cat, from this point of view, is just something ontic that you recognize as existing in the world (Potrč \& Strahovnik 2004).

What about semantics? Semantic deals with truth. And truth is many times construed as the correspondence between statements or thoughts and between the states of affairs or something similar existing in the world. Now, respecting the ontological difference in a semantic manner is to distinguish questions of $u l-$ timate ontology from questions of ontic everyday understanding. As we ask: "What is there? What does really exist out there?", we are asking a question under the contextual requirements of ultimate ontology. The contextual circumstances are very demanding in this case, and the proper answer under these high contextual requirements seems to be: "There is just one ultimately existing world out there." In the everyday contextual attitude though, we lower the semantic standards (Potrč \& Strahovnik 2005). Under such conditions then, we can allow for the existence of cats, stones and chairs. This is then the question of ontic contextual circumstances under which our inquiry tends to proceed.

Symphonies offer an intermediate possibility in respect to questions of existence. Cats exist in the everyday, common sense contextual attitude. Saying "Cat is here" is true under everyday common sense circumstances. Saying "World is here" is true under higher contextual deep ontological discourse circumstances. Saying:

(S) "Beethoven's Fifth Symphony has four movements"

is true as well. But it is true in the sense of describing how the world is. The appropriate correspondence is achieved if one says "The world is such that symphony has four movements". One thus refers to the World, but not in a direct, and rather in an indirect manner. Under these lower contextual requirements claims about cats and symphonies are true as the matter of indirect correspondence to the world, and not due to statements' direct correspondence to the world.

This means that despite its austere consequences, austere realistic monism allows for the truth of many common sense everyday statements and thoughts (Horgan \& Potrč 2006), provided that truth is construed as semantical indirect correspondence to the world, and not as the ultimate ontological correspondence to the world. These last kinds of statements are rarefied though. 
We have advanced the thesis that there is just one material world out there. (Horgan \& Potrč 2000, 2002, 2008). This thesis seems in contradiction with the views of common sense at first sight. But it turns out that, if one is sufficiently attentive at the dialectics of common sense once as it engages into reflective attitude, such a monistic view may be derived from common sense. Many everyday statements and thoughts are also recognized as true under such a view, provided that truth is construed as indirect correspondence, and not under stricter contextual conditions of direct correspondence to the world. In this sense the here sketched ontological monistic view respects ontological difference. Our inclusivist answer to the question about what there is may be thus formulated: "There exists just one ultimate material richly dynamical world, and despite the thus forthcoming denial of the existence of the many plenty of statements and thoughts figuring in our everyday talk are true, provided that the truth is construed as indirect and not as a direct correspondence to the world." Such a combined ontological cum semantic view seems a plausible and a well defendable position.

\section{Conflicts of Interest}

The authors declare no conflicts of interest regarding the publication of this paper.

\section{References}

Bartelj, L. (1994). Ontophilosophy. Ljubljana: LB.

Benveniste, É. (1958). Catégories de pensée et catégories de langue. Les Études Philosophiques, Nouvelle Série, 13, 419-429.

Blackburn, S. (1984). Spreading the Word: Groundings in the Philosophy of Language. Oxford: Oxford University Press.

Brentano, F. (1981). The Theory of Categories. The Hague: Nijhoff. https://doi.org/10.1007/978-94-009-8189-8

Diels, H. and Kranz, W. (1951). Die Fragmente der Vorsokratiker. Berlin: Weidmann.

Horgan, T. (1993). On What There Isn't. Philosophy and Phenomenological Research, 53, 693-700. https://doi.org/10.2307/2108094

Horgan, T., \& Potrč, M. (2000). Blobjectivism and Indirect Correspondence. Facta Philosophica, 2, 249-270.

Horgan, T., \& Potrč, M. (2002). Addressing Questions for Blobjectivism. Facta Philosophica, 2, 311-322.

Horgan, T., \& Potrč, M. (2006). Abundant Truth in an Austere World. In P. Greenough, \& M. Lynch (Eds.), Truth and Realism (pp. 137-161). Oxford: Clarendon Press. https://doi.org/10.1093/acprof:oso/9780199288878.003.0008

Horgan, T., \& Potrč, M. (2008). Austere Realism. Cambridge, MA: MIT Press. https://doi.org/10.7551/mitpress/9780262083768.001.0001

Mally, E. (1926). Grundgesetze des Sollens. Elemente der Logik des Willens. Graz: Leuschner \& Lubensky. https://doi.org/10.1093/mind/XXXVI.141.124-b

Potrč, M. (2003). Blobjectivist Monism. Repulsive Monism: One Dynamic BLOB and No 
Principles. In A. Baechli, \& K. Petrus (Eds.), Monism (pp. 125-155). Frankfurt: OntosVerlag.

Potrč, M., \& Strahovnik, V. (2004). Metaphysics: Ultimate and Regional Ontology. Informacion Filosofica, 1, 21-45.

Potrč, M., \& Strahovnik, V. (2005). Meinongian Scorekeeping. In A. Schramm (Ed.), Meinong Studies (pp. 309-330). Frankfurt: OntosVerlag.

Quine, W. V. (1948). On What There Is. Review of Metaphysics, 2, 21-38.

Quine, W. V. (1953). From a Logical Point of View. Cambridge: Harvard University Press.

Rey, G. (1983). Concepts and Stereotypes. Cognition, 15, 237-262. https://doi.org/10.1016/0010-0277(83)90044-6

Strahovnik, V. (2008). Introduction: Challenging Moral Particularism. In. M. Lance, M. Potrč, \& V. Strahovnik (Eds.), Challenging Moral Particularism (pp. 1-11). New York: Routledge.

Strahovnik, V. (2018). Metaphysical Monism, Statements about the Many and Moderate Error Theory. Analiza, 22, 79-92.

van Inwagen, P. (1990). Material Beings. Ithaca: Cornell University Press.

Zalta, E. (1988). Intensional Logic and the Metaphysics of Intentionality. Cambridge, MA: Bradford Books/The MIT Press. 